work; but the bowels did not act copiously until the 12th, after an active pill of calomel, gamboge, aloes, and soap.

Nov. 14th. He had no choleraic symptoms, but was weak, depressed, and without appetite. His bodily discomforts seemed now to arise from his still breathing an air that was full of a foul smell.

\section{DELIVERY DURING SLEEP.}

By Adolphus Samelson, M.D., Manchester.

The cases quoted from the Philadelphia Medical Reporter in the number of this Journal for Oct. 21st, p. 417, remind me of the following.

In the evening of February 22nd, 1844, I was sent for to Zabelsdorf, a village near Zehdenick, in the Uckermark, where I then resided (some thirty miles from Berlin), to attend a case of labour. Hannah Robde, the wife of a farm-labourer, about forty years old, of middle size, spare habit, and sallow complexion, having had eight children, of whom three were living, had passed easily through all her confinements; but, immediately after several of the births, especially after the eighth, she had for a short time been unconscious.

At about 1 A.M. on the above day, some blood was first observed to come from the vagina; however,it stopped again, when about noon a more copious flow set in, which now continued through the afternoon, and soon associated itself with unconsciousness. At 7.30 P.M.- - the time of my arrival-I found the os uteri pretty well dilated, and the membranes fairly distended, but the head placed quite to the right, and still so high that the particulars of the presentation could not be verified. Towards the right, partly in front, and partly to the side of the membranes, the placenta could be felt. The flooding had ceased. The woman did not recognise any one, and answered incoherently. The pulse, but little accelerated, and at first weak, became soniewhat fuller soon after my arrival. The skin perspired moderately. During the afternoon, one single pain had been felt. From time to time the membranes grew a little more tense, but the woman made no complaint; she only appeared to feel rather hot. She was placed on her left side-that opposed to the uterine tumour. She kept pretty quiet in this posture, appeared to sleep tranquilly, and after a time awoke a trifle more conscious. Soon, however, she relapsed into her doze. A few slight twitchings of the arms had been observed meanwhile. At ten o'clock the messenger returned, who had been sent for some ergot to the town, about six miles distant. At five minutes past 10, I gave half one of the ten-grain powders ordered. Almost immediately a labour came on ; but, even before it was observed, the woman exclaimed, "The water !' The nembranes were ruptured; the head had at once descended lower; it soon placed itself right in the middle of the relvis, and came further down. Fifteen minutes after the first, the woman got another dose of ergot, of two-and-a-half grains only (the midwife in attendance having mistakenly once more divided the half powder left); fresh labour-pains ensued, which, thirty-five minutes after 10, caused the face of the child to appear at the outlet. The entire body followed rapidly, and was immediately succeeded by a great gush of blood, welling out in two or three large waves. Within a few minutes more, the placenta, perfectly normal, came away; the funis was rather short.

The child, a middle-sized male, was some little time before he made himself heard. Only by degrees the woman's consciousness returned; she felt weary, and was much inclined to sleep. Soon after eleven o'clock, she had recovered her senses, and was not a little surprised at what had happened. The uterus kept contracting satisfactorily; nothing unusual further occurred. The number of pains had been seven or eight in all. As a stimulant, about three tablespoonfuls of poor Sauterne wine had been consumed during the process.

\section{SANGUINEOUS DISCHARGE FROM THE VAGINA OF AN INFANT.}

By J. Birchenall, Esq., Macclesfield.

ON the morning of August 25th, 1865, I was sent for in haste to Mrs. W., who had been suffering through the night from cramps in the abdominal muscles, recurring at intervals, which, as she was at the full period of utero-gestation, she regarded as the precursors of labour. On my arrival, I found that, half an hour previously, but without any other premonition, she felt as if the bowels would be moved, and withdrew to the water-closet for this purpose. Whilst she was there, a smart labour-pain supervened, by which the head of the child was protruded. The nurse, who was at hand, quickly replaced her on the bed; but the body of the child was not expelled until the moment I entered the room.

There was no pulsation in the cord, which was perfectly flaccid; and the child was asphyxiated, the head and neck being livid and cold, and a general pallor diffused over the body. As the action of the heart, however, had not entirely ceased, I endeavoured to restore it by applying flannels dipped in hot water to the chest, and sponges similarly charged to the groin and to the fontanelle. By the use of these means, the pulsations of the heart gradually increased in frequency and force; and, after the lapse of half an hour, there was a faint convulsive inspiration, which was repeated at intervals during from five to ten minutes more, when the breathing slowly quickened into its natural state.

The child was a female, of large development, as compared with the children the lady had previously borne.

On the morning of the fifth day after birth, the nurse was startled by a discharge of blood on the napkin of the infant, to which she called my attention, stating, as her firm belief, that it proceeded "from the female passage". She produced a napkin which had been recently removed, upon which there was a patch, of about the size of a crown-piece, of a florid muco-sanguineous discharge. It was obvious that the blood could not have proceeded from the bowels, as the fæcal discharge occupied a distinct patch on the napkin in this, as well as in every previous and subsequent instanoe. On separating the outer labia, I found the internal surface suffused with blood; and the vulva, when cleansed by sponging, uniformly injected. On the third day, the vaginal discharge assumed a somewhat brownish colour; but on the fourth it became florid as at first, and terminated on the fifth with a dark clot, such as not unfrequently occurs at the close of the usual menstrual period. There was no marked turgescence in any portion of the sexual appendages.

Although there has been no recurrence of this particular phenomenon, it is worthy of note, as something like an approximative coincidence, that, at the end of the month precisely, from the period first indicated, there was a transudation of sero-sanguineous fluid from the mucous surface of the bowels, like that which is ordinarily seen in the milder forms of dysentery, which continued a day or two only, but without any deviation from the natural state of the alvine evacuations. 